\title{
A review of the British Journal of Sports Medicine 1991-5
}

\author{
Bruce Thompson
}

\begin{abstract}
Objective-To review 5 years of the British Fournal of Sports Medicine (BJSM) to assess the nature of articles published, look at which specialities and nationalities were contributing most frequently, and analyse the numbers of subjects involved in the studies.

Methods-Data were collated from all original papers, review articles, and case reports from March 1991 to December 1995.

Results-Authors from 35 different countries contributed a total of 282 papers in the 5 year period, with medical authors (118) predominating. They covered a wide range of subjects in all aspects of sports medicine. There were few randomised controlled studies (9).

Conclusions-The BJSM has wide international input which covers all aspects of sports medicine. A greater number of large randomised controlled studies would, however, provide a firmer statistical basis for future research and injury management. There is also scope for development of the BJSM especially in the areas of education, innovations, and the practical applications of research. (Br f Sports Med 1996;30:354-355)
\end{abstract}

Key terms: review; sports medicine; randomised controlled trial

Sports medicine has increasingly become an academic specialty in its own right and with the development of a network of sports medicine institutes and departments in the United Kingdom it is worthwhile to review the content of the British Fournal of Sports Medicine (BJSM). This is especially relevant as it is the only journal specifically covering the specialty published in the United Kingdom and has recently had a change of Editor.

\section{Methods}

All editions of the journal published between March 1991 and December 1995 inclusive were reviewed. Every original paper, review article, and case report was analysed for the following: (1) the name of the lead author, (2) named specialty of lead author, (3) nationality of lead author, (4) main topic covered, (5) type of study performed, (6) numbers of subjects involved, and (7) frequency of publication by each author.

These figures were collated into the accompanying tables. In some cases the field of specialty was not given and these were then classified under "miscellaneous." In the case of specialty of lead author there were many varieties of department considered under the auspices of health/physical education/sports science and these were all included under the "Sports Science" banner. Nationality of lead author was assessed from the contact address given, as it was felt that this reflected most accurately where the work relating to the article had been carried out. In total, 282 articles were analysed.

\section{Results and discussion}

It can be seen from the tables that a wide range of topics has been published in the BJSM, reflecting the diverse nature of sports medicine. It is worth noting, however, that the 36 articles on injury in a specific sport were very similar in layout and structure and that they tended to differ only in the sport analysed. These were often a "minority sport" - Frisbee injury, waterbike injury, Tarzan swings, etc. While it is interesting to see the patterns of injury in different sports, the numbers of injuries recorded (average 230) and the time scale of the audit (average 1.9 years) were often small. In fact, if a 10 year study of trampoline injuries from New Zealand is removed, the statistics become much smaller, averaging 152 subjects and 1.5 years respectively.

\section{Table 1 Topics covered}

\begin{tabular}{lc}
\hline Topic & No of articles \\
\hline Injury-attributed by sport & 36 \\
Injury-attributed by anatomical region & 39 \\
Relating to medical conditions & 41 \\
Sports science & 59 \\
Psychology/psychiatry & 10 \\
Anthropometry & 9 \\
Treatment types & 16 \\
Sport-specific articles & 23 \\
Diagnostic investigations & 6 \\
Anatomical problems & 25 \\
Miscellaneous & 18 \\
\hline
\end{tabular}

Accepted for publication 28 February 1996 
Table 3 Average numbers in study

\begin{tabular}{lr}
\hline Case report & 2 \\
Controlled trial & 80 \\
Randomised controlled trial & 67 \\
\hline
\end{tabular}

Table 4 Frequency of publication by author

\begin{tabular}{lr}
\hline One publication & 206 \\
Two publications & 22 \\
Three publications & 8 \\
Four publications & 2 \\
\hline
\end{tabular}

Table 5 Specialty of lead author

\begin{tabular}{lr}
\hline Orthopaedics & 40 \\
Sports medicine & 20 \\
Other medical/surgical & 58 \\
Sports science & 69 \\
Physiotherapy & 9 \\
Psychology & 7 \\
Other classified & 30 \\
Miscellaneous & 5 \\
\hline
\end{tabular}

Table 6 Nationality of lead author

\begin{tabular}{lr}
\hline England & 92 \\
USA & 25 \\
Scotland & 15 \\
Australia & 12 \\
New Zealand & 8 \\
Canada & 8 \\
Ireland & 8 \\
Hong Kong & 6 \\
Japan & 5 \\
Rest of World & 58 \\
Total number of different countries & 35 \\
\hline
\end{tabular}

Also care must be taken to keep articles relevant - surely an article entitled "A formula for comparison of selected sport ball compressibility" does not come under the sports medicine umbrella.

It is often said that the gold standard of research is the randomised control study. This audit has shown that a small number of randomised control studies (9) were published in the 5 year period studied and that these had a low average number of subjects (67). Perhaps

Table 2 Type of study

\begin{tabular}{lcl}
\hline Study type & Total No & Percentage \\
\hline Literature review & 34 & 12 \\
Case report & 35 & 12 \\
Review of subject & 57 & 20 \\
Observational/descriptive & 115 & 41 \\
Cohort & 2 & 1 \\
Controlled trial & 25 & 9 \\
Randomised controlled trial & 9 & 3 \\
Miscellaneous & 5 & 2 \\
\hline
\end{tabular}

the advent of a national network of sports medicine institutes will allow an improvement.

The large number of different authors (238), nationalities, and specialties can only be an encouraging sign. It shows that there is a broad base of researchers in the subject and also underlines international interest in the journal. This review confirms that the stated aim of the British Association of Sport and Medicine (BASM) "to promote research" is bearing fruit.

Whether or not a journal of this type should be purely a "journal of record" and judged according to the number or quality of original articles, reviews, or case reports or whether it should be a "journal of communication", judged by its popular appeal to its readership, is open to debate. As a clinician I feel the journal could be expanded to include a series of nationally agreed standards for the management of the more common sports injuries. Areas such as the "prescription of exercise" which are currently topical could also be the focus of a regular section in the journal-if the American College of Sports Medicine can provide clinical guidelines on these areas why should the United Kingdom lag behind? There is scope for articles on the latest innovations and their impact on sports medicine, for example magnetic resonance imaging. I would be fascinated to read educated debate on controversial issues such as the "Boxing Debate" or "Drugs in Sport". Items such as these could generate more letters to the editor and in turn lead to more fertile discussion in sports medicine circles. Perhaps other areas which could be developed would include a photographic section of unusual cases, a section dealing with eponymous clinical tests and signs such as Jobe's or Lachman's tests, or even an anecdotal section.

\section{CONCLUSION}

While this review has highlighted many of its positive aspects, the BJSM must adapt and develop with changing times. I wonder how a review of the next five years will compare.

\section{Bibliography}

Silagy C, Jewell D. Review of 39 years of randomized controlled trials in the British Journal of General Practice. $\mathrm{Br} \mathcal{F}$ Gen Pract 1994;44:359-63.

Pringle M, Churchill R. Randomised controlled trials in general practice. $B M \Im$ 1995;311:1382-3.

mith R. Promoting research into peer review. BMF 1994;309. 1382-3.

MacAuley D. READER: an acronym to aid critical reading by general practitioners. Br f Gen Pract 1994;44:83-5.

Dowell LJ, Krebs G. A formula for comparison of selected sport ball compressibility. Br f Sports Med 1991;25:34-7. 